\title{
O piso salarial em São Paulo Desvalorização dos professores
}

\author{
Andreza Barbosa* \\ Maria José da Silva Fernandes*
}

RESUMO: O artigo discute a situação atual dos salários e jornadas de trabalho dos professores na rede pública estadual paulista a fim de verificar a adequação à Lei $n^{0}$ 11.738, de 2008, que criou o piso salarial do magistério. Evidencia-se que o estado sistematicamente dribla a legislação federal, adequando, de forma questionável, a jornada de trabalho dos professores à lei do piso, e pagando, este ano, remuneração abaixo do estabelecido legalmente, o que amplia a desvalorização dos professores.

Palavras-chave: Piso salarial. Valorização do magistério. Remuneração docente. Rede pública estadual paulista. Trabalho Docente.

\section{Introdução}

A importância da educação tem sido afirmada de forma recorrente em nossa sociedade, ainda que essa importância não se traduza em ações concretas e efetivas em prol da qualidade do ensino. Os professores são os sujeitos que, tradicionalmente, têm sido incumbidos da tarefa de educar no âmbito escolar. Dessa forma, podemos concluir que, se a educação é socialmente importante e se os professores são os principais sujeitos por ela responsáveis, logo, o trabalho docente é fundamental

* Doutorado em Educação. Professora do Programa de Pós-Graduação em Educação da Universidade Metodista de Piracicaba (Unimep), integrando o Núcleo de Estudos e Pesquisas Trabalho Docente, Formação de Professores e Políticas Educacionais. Piracicaba/SP - Brasil. E-mail: <andrezab27@gmail.com>.

** Doutorado em Educação. Professora assistente no Departamento de Educação da Universidade Estadual Paulista (FC/Unesp), Campus Bauru e no Programa de Pós-Graduação em Educação Escolar (FCL/Unesp), Campus Araraquara. Bauru/SP - Brasil. E-mail: <mjsfer@fc.unesp.br>. 
e, como tal, deve ser valorizado. Apesar de isso parecer óbvio, pesquisas têm apontado um cenário de precarização e proletarização do trabalho docente (OLIVEIRA, 2007; DUARTE, 2011), bem como de redução da atratividade da carreira docente no Brasil (GATTI et. al., 2010; TARTUCE; NUNES; ALMEIDA, 2010).

Nesse cenário, os planos de carreira e remuneração do magistério são frequentemente apontados como elementos importantes na tentativa de estabelecer a valorização dos professores. Ao tratar dessa temática, Gatti (2012, p. 90) afirma que os planos de carreira "[...] efetivamente, refletem o reconhecimento social e político desses profissionais". Há que se reconhecer, no entanto, que o fato de um sistema de ensino ter um plano de carreira não garante, por si só, a valorização dos professores. Monlevade (2000) aponta que a valorização docente deve se apoiar em uma remuneração digna, contando os professores com formação inicial e continuada de qualidade, além de ter uma estrutura de carreira capaz de fixá-los ao sistema de ensino no qual atuam. É necessário também uma jornada de trabalho que preveja tempo destinado aos alunos em sala de aula e tempo para a realização das atividades extraclasse.

Apesar de reconhecer que um plano de carreira contribui para a valorização dos professores e deve dar conta dos vários elementos apontados por Monlevade (2000), neste artigo, nos deteremos na remuneração e jornada de trabalho docente, uma vez que ambos foram regulamentados pela Lei n⿳⺈ 11.738, de 2008, que criou o piso salarial profissional nacional. A lei do piso se constituiu como importante estratégia para a valorização docente, uma vez que todos os estados e municípios brasileiros devem se adequar a essa exigência legal, garantindo um valor mínimo de remuneração a seus professores e, também, uma jornada de trabalho que destine, no mínimo, 1/3 das horas às atividades extraclasse.

Apesar da importância dessa lei, desde a sua criação, alguns estados e vários municípios não têm cumprido parcial ou integralmente o que é previsto (FERNANDES, 2013). O estado de São Paulo, mesmo sendo a mais rica unidade da federação, tem estabelecido, nos últimos anos, ações e estratégias que aprofundam a degradação salarial dos professores da rede pública, o que nos leva a questionar o pleno cumprimento da lei do piso por parte da Secretaria da Educação.

Desta forma, buscamos neste artigo discutir a situação atual dos salários e jornadas de trabalho dos professores na rede pública estadual paulista de ensino com vistas a verificar sua adequação à Lei nº 11.738, de 2008 e, também, traçar algumas breves considerações sobre os desdobramentos para a valorização dos professores. As considerações feitas aqui partiram da discussão da bibliografia pertinente ao tema, da análise da legislação federal e, também, das informações levantadas sobre remuneração e jornada de trabalho na rede pública estadual paulista. 


\section{Um breve olhar a partir da recente legislação brasileira}

A Organização das Nações Unidas para a Educação, a Ciência e a Cultura (Unesco), em um documento de 1966, intitulado Recomendação Relativa à Condição de Professores, destaca na indicação de n⿳0 114 que o pagamento de salários dignos seria uma forma de fazer com que a profissão docente fosse respeitada e valorizada pela sociedade:

Entre os vários fatores que afetam a condição do professor, deveria ser dada uma atenção muito particular à remuneração, uma vez que, nas condições do mundo atual, outros fatores, como a posição e consideração que a sociedade lhes reconhece e o grau de apreço pela importância das suas funções, estão grandemente dependentes, tal como em outras profissões similares, da situação econômica que se lhes acorda. (UNESCO, 1966, p. 44).

No mesmo documento, em sua recomendação de n⿳ำ 115, é destacado que a remuneração deveria refletir a importância da educação e do professor para a sociedade, ser equivalente ou maior que a remuneração de profissões análogas e assegurar aos professores razoável nível de vida, de modo a permitir seu aprimoramento profissional e cultural, considerando-se a experiência, qualificação e responsabilidade da função. Evidencia-se nesse documento a relação entre remuneração e valorização docente, o que também tem sido observado na legislação brasileira recente e em pesquisas que envolvem a temática (MONLEVADE, 2000; ROCHA, 2009; BARBOSA, 2011).

Neste sentido, a própria Constituição Federal de 1988 em seu artigo 206 afirma, como princípios sob os quais o ensino deveria ser ministrado, a valorização dos profissionais da educação e o estabelecimento de um piso salarial profissional nacional:

Art. 206. O ensino será ministrado com base nos seguintes princípios:

$[\ldots]$

V - valorização dos profissionais da educação escolar, garantidos, na forma da lei, planos de carreira, com ingresso exclusivamente por concurso público de provas e títulos, aos das redes públicas;

\section{$[\ldots]$}

VIII - piso salarial profissional nacional para os profissionais da educação escolar pública, nos termos de lei federal. (BRASIL, 1988).

Também o texto da Lei de Diretrizes e Bases da Educação Nacional (LDB) nํ⒐394, de 1996, prevê, em seu artigo 67, que os planos de carreira do magistério público deverão prever formas de valorização dos profissionais da educação mediante a garantia, dentre outros elementos, de piso salarial profissional como podemos observar no excerto seguinte: 
Art. 67. Os sistemas de ensino promoverão a valorização dos profissionais da educação, assegurando-lhes, inclusive nos termos dos estatutos e dos planos de carreira do magistério público:

$[\ldots]$

III - piso salarial profissional. [...] (BRASIL, 1996)

A Lei no 11.494, de 2007, ao regulamentar o Fundo de Manutenção e Desenvolvimento da Educação Básica e de Valorização dos Profissionais da Educação (Fundeb), também reforça a necessidade de estados, municípios e Distrito Federal elaborarem seus planos de carreira e remuneração do magistério de modo a garantir um vencimento condigno aos profissionais da educação na rede pública. Essa lei ainda definiu prazo até 31 de agosto de 2007 para que o poder público estabelecesse o piso salarial nacional dos professores. (BRASIL, 2007).

Apesar do prazo estabelecido, foi somente em 16 de julho de 2008 que o piso salarial profissional nacional destinado aos profissionais do magistério foi aprovado por meio da Lei $n^{0} 11.738$. Inicialmente o valor mínimo fixado correspondia a $\mathrm{R} \$ 950,00$ para professores com formação em nível médio, com jornada de trabalho de 40 horas semanais, sendo o valor corrigido anualmente de acordo com o valor aluno mínimo do Fundeb. A lei definiu ainda o limite máximo de $2 / 3$ da jornada de trabalho semanal dos professores a serem destinados às atividades com alunos (BRASIL, 2008).

Embora tenham surgido críticas quanto à lei do piso, sobretudo ao valor inicialmente definido, temos que considerar que a aprovação de um piso salarial nacional para os professores atendeu a uma reivindicação histórica da categoria, exercendo importante função ao fixar um patamar mínimo de dignidade para os professores brasileiros que viviam condições tão díspares no território nacional. (MONLEVADE, 2000). Nesse sentido, o estabelecimento de um piso salarial para os professores é elemento fundamental na busca pela valorização profissional.

Há que se destacar também que o Conselho Nacional de Educação (CNE), após consultas e discussões em várias instâncias, elaborou a Resolução CNE/CEB nº 2, de 2009, fixando as diretrizes para os planos de carreira e remuneração dos profissionais do magistério da educação básica pública. Embora esse documento não tenha o caráter de lei, ele orienta os princípios a serem observados por estados e municípios na formulação de seus planos de carreira e remuneração do magistério. Um desses princípios é o "IV - reconhecimento da importância da carreira dos profissionais do magistério público e desenvolvimento de ações que visem à equiparação salarial com outras carreiras profissionais de formação semelhante" (BRASIL, 2009). Reconhece-se, portanto, a importância da remuneração para o reconhecimento social da carreira docente.

Por fim, mais recentemente, a Lei oㅡㄴ 13.005, de 2014, que aprovou o Plano Nacional de Educação (PNE) para o período de 2014 a 2024, estabeleceu como meta de número 
17 “valorizar os (as) profissionais do magistério das redes públicas de educação básica de forma a equiparar seu rendimento médio ao dos (as) demais profissionais com escolaridade equivalente, até o final do sexto ano de vigência deste PNE" (BRASIL, 2014) e, como meta de número 18 :

Assegurar, no prazo de 2 (dois) anos, a existência de planos de carreira para os (as) profissionais da educação básica e superior pública de todos os sistemas de ensino e, para o plano de Carreira dos (as) profissionais da educação básica pública, tomar como referência o piso salarial nacional profissional, definido em lei federal [...]. (BRASIL, 2014).

Fica evidente, portanto, que na recente legislação nacional brasileira a valorização dos profissionais da educação está diretamente vinculada à criação de planos de carreira e remuneração do magistério. Dessa forma, também é possível compreender que não basta que os planos de carreira estabeleçam qualquer padrão de remuneração para que os professores sejam valorizados. De imediato, é necessário que se cumpra a lei do piso salarial dos professores quanto ao valor mínimo e, também, quanto à composição da jornada de trabalho. E, posteriormente, é necessário que se caminhe no sentido de equiparar a remuneração dos professores com a de outros profissionais com mesma formação, como prevê o PNE atual. Neste sentido, se a legislação nos permite reconhecer avanços em relação a outros momentos históricos, também nos indica que ainda há muito a ser feito no que se refere à valorização docente.

\section{Rede pública estadual paulista e sua difícil relação com a lei do piso}

São Paulo é o mais populoso dos estados brasileiros e concentra o mais expressivo número de matrículas na educação básica do País. Segundo a Sinopse Estatística de 2014, o Brasil totalizava 49.771.371 matrículas na educação básica, das quais 10.320.191 concentravam-se no estado de São Paulo (INEP, 2014). Consequentemente, o número de funções docentes nesse estado também registra valor que se destaca diante do total nacional, já que de 2.403.682 professores brasileiros, quase 500.000 estão no estado de São Paulo (INEP, 2014).

O site da Secretaria da Educação do Estado de São Paulo (SEE-SP) destaca que a rede pública paulista de ensino é a maior do País, com 5,3 mil escolas, 230 mil professores, 59 mil servidores e mais de quatro milhões de alunos atendidos no ensino fundamental e ensino médio (SEE-SP, 2016a). Se considerarmos os dados mais recentes disponibilizados pela Coordenadoria de Gestão de Recursos Humanos (CGRH) da mesma secretaria, o número de professores que compunha o quadro docente na rede pública estadual paulista em fevereiro de 2016 era de 200.032 (SEE-SP, 2016b), ou seja, é uma rede de ensino grandiosa. 
O estado de São Paulo é também o estado mais rico do País. Segundo dados divulgados pelo IBGE (2014), o Produto Interno Bruto (PIB) paulista, em 2012, ficava em torno de 1,4 trilhões de reais, o que correspondia a uma participação de 32,1\% no PIB nacional. (IBGE, 2014). Embora seja considerado o estado mais rico da federação, concentrando ainda a maior arrecadação de impostos (RECEITA FEDERAL DO BRASIL, 2016), os salários dos professores paulistas são considerados baixos, antes mesmo da aprovação da lei do piso (SOUZA, 1999; LAPO; BUENO, 2003; BARBOSA, 2011). Tal situação se torna ainda mais grave se considerarmos o elevado custo de vida na maioria das cidades paulistas.

Ainda que considerado um baixo valor, quando foi aprovada a Lei nº 11.438 de 2008, o salário dos professores da rede pública estadual paulista era $37,8 \%$ superior ao valor estabelecido pelo piso - $\mathrm{R} \$ 950,00$ por uma jornada de 40 horas semanais para professores com formação em nível médio. Nesse mesmo ano, o salário base do professor de educação básica I (PEB I) que atuava nos anos iniciais do ensino fundamental da rede pública paulista era de R\$1.309, 17 (SÃO PAULO, 2009). Ocorre, porém, que legalmente a correção do valor do piso salarial nacional é feita com base na variação do valor anual mínimo por aluno do Fundeb. A tabela abaixo mostra a evolução do valor do piso salarial dos professores, do ano seguinte à aprovação da lei que o instituiu até 2016:

\section{Tabela 1 - Valor do piso salarial profissional nacional por ano - 2009 a 2016}

\begin{tabular}{cc}
\hline Ano & Valor (em reais) \\
\hline 2009 & 950,00 \\
\hline 2010 & 1024,67 \\
2011 & 1187,08 \\
\hline 2012 & 1451,00 \\
\hline 2013 & 1567,00 \\
\hline 2014 & 1697,00 \\
2015 & 1917,78 \\
\hline 2016 & 2135,64 \\
\hline
\end{tabular}

Fonte: Elaborada pelas autoras com base em dados disponíveis no site do Ministério da Educação (MEC, 2016).

No período de 2009 a 2016, portanto, o piso salarial nacional teve um aumento de $125 \%$. Segundo o atual ministro da educação, Aloizio Mercadante, em depoimento ao portal de notícias G1 publicado em 14/01/2016, tratou-se de um aumento real de 46\% acima da inflação acumulada no período. (G1, 14/01/2016). O mesmo não aconteceu com os salários dos professores da rede pública estadual paulista, sobretudo se consideramos o salário base do professor ingressante nos anos iniciais do ensino fundamental (PEB I) em uma jornada de 40 horas semanais. 
É importante registrar que a rede pública estadual paulista de ensino diferencia os salários base dos professores que atuam nos anos iniciais do ensino fundamental (PEB I) com relação aos salários dos que atuam nos anos finais do ensino fundamental e ensino médio (PEB II) ${ }^{1}$. No ano de 2009, logo após a aprovação da lei do piso, um PEB I, com 40 horas de trabalho, recebia $R \$ 1.309$, 17, enquanto um PEB II recebia $R \$ 1.515,52$, pela mesma carga horária, conforme dados da Lei Complementar nº 1094 de 16 de julho de 2009 (SÃO PAULO, 2009).

Mais recentemente, segundo dados disponibilizados pelo Sindicato dos Professores do Ensino Oficial do Estado de São Paulo (Apeoesp), em seu site na internet, o valor do salário base do PEB I, em julho de 2014, para uma jornada de 40 horas semanais era de $\mathrm{R} \$ 2.086,93$. Como não houve reajuste salarial desde então, esse valor continua valendo para o ano de 2016, como ilustra a tabela seguinte.

Tabela 2 - Salário base professores paulistas - julho 2014

\begin{tabular}{l|c|c}
\hline \multirow{2}{*}{\multicolumn{1}{c}{ Classe }} & \multicolumn{2}{c}{ Inicial } \\
\cline { 2 - 3 } & Hora/aula & Salário Base \\
\hline Classe dos docentes (24h) & $\mathrm{R} \$ 10,43$ & $\mathrm{R} \$ 1.252,16$ \\
\hline Professor de Educação Básica I & $\mathrm{R} \$ 12,08$ & $\mathrm{R} \$ 1.449,53$ \\
\hline Professor de Educação Básica II & & $\mathrm{R} \$ 1.565,19$ \\
Classe dos docentes (30h) & $\mathrm{R} \$ 10,43$ & $\mathrm{R} \$ 1.811,91$ \\
Professor de Educação Básica I & $\mathrm{R} \$ 12,08$ & \\
Professor de Educação Básica II & & $\mathrm{R} \$ 2.086,93$ \\
\hline Classe dos docentes (40h) & $\mathrm{R} \$ 10,43$ & $\mathrm{R} \$ 2.415,89$ \\
\hline Professor de Educação Básica I & $\mathrm{R} \$ 12,08$ & \\
\hline Professor de Educação Básica II &
\end{tabular}

Fonte: Apeoesp (2016).

Ao comparamos, portanto, o valor inicialmente estabelecido pela lei que instituiu o piso salarial (para professores com formação em nível médio em jornada de 40 horas semanais) com o valor pago aos professores dos anos iniciais do ensino fundamental na rede pública estadual paulista, em 2009 (para a mesma jornada de 40 horas), percebemos que os paulistas recebiam naquele momento $37,8 \%$ a mais que o piso, como já apontamos aqui. No entanto, se compararmos o valor estabelecido pelo piso salarial nacional para 2016 e o valor do salário base dos professores dos anos iniciais do ensino fundamental em vigor neste mesmo ano (considerando o valor de julho de 2014), veremos que o salário da rede paulista está 2,28\% abaixo do valor estabelecido pelo piso. A tabela abaixo ilustra isso. 
Tabela 3 - Piso salarial nacional e salário base professores paulistas - 2009 e 2016

\begin{tabular}{|c|c|c|c}
\hline Ano & $\begin{array}{c}\text { Piso salarial nacional } \\
\text { - jornada de 40h/ } \\
\text { semanais } \\
\text { (em reais) }\end{array}$ & $\begin{array}{c}\text { Salário base professor PEB } \\
\text { I - estado de São Paulo - } \\
\text { jornada de 40h/semanais }\end{array}$ & $\begin{array}{c}\text { Diferença } \\
\text { piso } \\
\text { nacional e } \\
\text { salário base } \\
\text { paulista }(\%)\end{array}$ \\
\hline 2009 & 950,00 & (em reais) & $+37,8 \%$ \\
\hline 2016 & $2.135,64$ & $1.309,17$ & $-2,28 \%$ \\
\hline Aumento $(\%)$ & $+125 \%$ & $2.086,93$ & \\
\hline
\end{tabular}

Fonte: Elaborado pelas autoras com base em dados disponibilizados pelo MEC (2016), São Paulo (2009) e Apeoesp (2016).

Fica evidente, portanto, que o estado de São Paulo, mesmo sendo o mais rico do País, não está pagando aos seus professores o valor mínimo estabelecido pela Lei Federal n⿳ํㅡㄴ 11.438, de 2008. Isso foi admitido pelo atual secretário da educação paulista, José Renato Nalini, em depoimento ao jornal O Estado de São Paulo (Estadão) publicado em 9 de abril de 2016. Na referida matéria, o secretário afirma que São Paulo precisa reajustar os salários dos professores da rede pública paulista porque desde janeiro de 2016 (quando o MEC fez o último reajuste do valor do piso salarial nacional) o estado não está cumprindo o estabelecido pela lei federal: "Nós estamos cuidando disso, porque vamos ter de cumprir (o piso nacional), estamos vendo de onde podemos tirar recurso para atender porque pela primeira vez, infelizmente, São Paulo vai ficar abaixo do piso". (O ESTADO DE SÃO PAULO, 09/04/2016).

Apesar do depoimento do secretário, os professores paulistas continuam sem reajuste salarial desde 2014 e em março de 2016 o governo do estado de São Paulo propôs trocar o pagamento do Bônus Mérito², referente ao ano de 2015, que deveria ser pago no final de março de 2016, por um reajuste geral de 2,5\% para os professores, em uma evidente tentativa de resolver o problema de adequação à lei do piso. Como os professores não aceitaram a troca, o descumprimento da lei permanece.

A lei do piso salarial dos professores também estabelece que a jornada de trabalho deve ser composta de forma a destinar, no máximo, $2 / 3$ do total de horas para as atividades em sala de aula. Ou seja, $\mathrm{o} \frac{1}{3} 3$ restante deve ser destinado às atividades extraclasse necessárias ao desenvolvimento do trabalho docente, como preparação de aulas, correção de atividades dos alunos etc. Também com relação a este aspecto da lei do piso, o estado de São Paulo tem adotado conduta controversa, como já sinalizado por Fernandes e Barbosa (2014). A jornada de trabalho dos professores da rede pública estadual paulista se organizava, tradicionalmente, em horas-aula, com duração de 50 minutos no período diurno e 45 minutos no período noturno. Dessa forma, "[...] um professor com jornada integral, poderia ter, no máximo, 33 aulas (horas-aula com alunos) que, somadas às 7 horas de trabalho extraclasse, somariam as 40 horas que compõem essa jornada." (FERNANDES; BARBOSA, 2014, p. 131). 
Como a Ação Direta de Inconstitucionalidade (Adin) que questionava a determinação da lei do piso no tocante à composição da jornada de trabalho dos professores só foi julgada e considerada constitucional em 2011, o estado de São Paulo deveria adequar-se obrigatoriamente à legislação nacional, o que tentou fazer em 2012. Para dar conta de adequar a jornada de trabalho dos professores paulistas à lei do piso, num pensamento lógico, esperava-se que, em uma jornada de 40 horas, o professor passasse a ter no máximo 27 horas com alunos (2/3) e as 13 horas restantes ( $1 / 3)$ seriam destinadas ao trabalho extraclasse.

No entanto, o estado de São Paulo se valeu estrategicamente da possibilidade prevista na legislação brasileira de organizar as horas-aula em 60, 50 ou 45 minutos, e considerou que a jornada integral era de 40 horas de 60 minutos, o que totalizaria 2.400 minutos. Se dividirmos esse valor pela duração da hora-aula no período diurno, que é de 50 minutos, teremos uma jornada de 48 horas-aula semanais. Por fim, se pensarmos que $1 \frac{1}{3}$ de 48 seriam 16 horas-aula, e se transformarmos essas 16 horas-aula em horas-relógio novamente, chegaremos a 13,33 horas relógio, exatamente $1 \frac{1}{3}$ de 40 horas-relógio. Com essa manobra, o estado concluiu então que os professores trabalhavam 48 horas-aula e que deveriam destinar, portanto, 16 horas-aula ao trabalho extraclasse. Considerando que os professores trabalhavam 33 horas-aula com alunos, em sala de aula, restavam, apenas, 15 horas para o trabalho extraclasse, o que implicava a necessidade de reduzir uma hora-aula com aluno para que a jornada estivesse adequada à lei do piso (FERNANDES; BARBOSA, 2014).

A Resolução nº 8, de 19 de janeiro de 2012 (SÃO PAULO, 2012) alterou, portanto, a composição da jornada de trabalho dos professores da rede pública paulista para tentar adequá-la ao piso. A tabela 4 ilustra as mudanças na jornada.

Tabela 4 - Composição da jornada de trabalho docente na rede pública estadual paulista antes e depois da Resolução no 8, de 19 de janeiro de 2012

\begin{tabular}{|c|c|c|c|c|c|}
\hline \multicolumn{6}{|c|}{ Jornada atual para 40 horas semanais } \\
\hline & Horas & Minutos & $\begin{array}{c}\text { Aulas (50 } \\
\text { min) }\end{array}$ & $\%$ & \\
\hline Total & 40,0 & 2.400 & 48 & 100 & \\
\hline Em Classe & 27,5 & 1.650 & 33 & 68,7 & \\
\hline Extraclasse & 12,5 & 750 & 15 & 31,3 & \\
\hline \multicolumn{6}{|c|}{ Nova Jornada para 40 horas semanais (período diurno) } \\
\hline & Horas & Minutos & $\begin{array}{c}\text { Aulas (50 } \\
\text { min) }\end{array}$ & $\%$ & \\
\hline Total & 40,0 & 2.400 & 48 & 100 & $1 / 1$ \\
\hline Em Classe & 26,6 & 1.600 & 32 & 66,6 & $2 / 3$ \\
\hline Extraclasse & 13,3 & 800 & 16 & 33,3 & $1 / 3$ \\
\hline
\end{tabular}


Essa medida frustrou as expectativas da categoria docente, que esperava ter reduzido o tempo de atividade com aluno para 27 horas, adequando-se a jornada de trabalho à lei do piso. Mas, os professores também se surpreenderam com a afirmação de que a jornada de trabalho dos professores da rede pública paulista era organizada em horas-relógio (de 60 minutos) e que os professores trabalhavam 48 horas-aula e não 40 como pensavam (por décadas, a rede se organizou em função das horas-aula). Sobre isso, Fernandes e Barbosa (2014, p. 136) destacam que:

Além de ser uma jornada absurda, dadas as exigências e especificidades do trabalho docente [...] esta nunca correspondeu ao praticado na rede pública estadual, uma vez que, até aquele momento, a jornada máxima que um professor poderia assumir era de 40 horas-aula e não 48 horas-aula (ou 40 horas-relógio, como se argumentou na resolução no 2, de 2012).

Essa manobra de conversão das horas-aula em horas-relógio parece ter sido o subterfúgio encontrado pelo estado de São Paulo para não arcar com os custos de uma redução maior da jornada de trabalho docente com aluno, medida esta que implicaria na contratação de mais professores. $\mathrm{O}$ estabelecido pela lei do piso sobre a jornada que poderia ter a importante função de reduzir a carga de trabalho dos professores paulistas teve, no entanto, pouco impacto na organização das horas efetivamente trabalhadas em sala de aula.

Considerando esses aspectos, evidencia-se o fato do estado de São Paulo ter adotado uma medida controversa, uma manobra política, para fazer a adequação da jornada de trabalho dos professores à lei do piso salarial nacional, o que pode ser interpretado como não reconhecimento da natureza e da especificidade do trabalho docente. Agora, mais uma vez, o estado mais rico do País está descumprindo essa importante lei quanto ao valor mínimo da remuneração docente. Num estado em que a nefasta política de bonificação se sobrepõe à política salarial e de valorização da carreira, evidencia-se o aprofundamento da precarização do trabalho dos professores.

\section{Considerações finais}

Mesmo pagando salários considerados baixos aos seus professores (SOUZA, 1999; BARBOSA, 2011), o estado de São Paulo ainda dava conta, até o início de 2016, de cumprir o valor mínimo estabelecido pela Lei $\mathrm{n}^{0}$ 11.738, de 2008, que criou o piso salarial dos professores. Quando essa lei foi aprovada, o salário dos professores paulistas ainda era superior ao mínimo estabelecido. No entanto, ao longo dos anos, o arrocho salarial sofrido pelos docentes do estado de São Paulo (decorrente da ausência de uma política séria de valorização docente) fez com que, desde janeiro de 2016, a remuneração desses profissionais estivesse abaixo do estabelecido pela lei federal. Soma-se a esse 
preocupante fato a forma questionável adotada pelo estado para adequar a jornada de trabalho docente de sua rede de ensino ao estabelecido pela lei do piso.

Diante disso, afirmamos que o estado de São Paulo não tem cumprido a lei do piso salarial nacional. Podemos afirmar ainda que esse estado está em desacordo com a legislação brasileira, que vincula a valorização do magistério ao piso salarial dos professores. O cumprimento da lei do piso é uma medida importante para a valorização dos professores, portanto, ao não cumprir a legislação, podemos supor que os professores paulistas (que vivem num estado com elevado custo de vida) estão submetidos a um grave processo de desvalorização de seu trabalho que se expressa, sobretudo, numa parca remuneração. Essa desvalorização pode ter efeitos nefastos sobre a qualidade da educação paulista, sobretudo porque tem contribuído para, cada vez mais, reduzir a atratividade e ampliar o abandono da docência (LAPO; BUENO, 2003; GATTI et. al., 2010; TARTUCE; NUNES; ALMEIDA, 2010; CASSETTARI; SCALDELAI; FRUTUOSO, 2014), além de ter desdobramentos sobre o trabalho realizado em sala de aula pelo professor que permanece na rede (BARBOSA, 2011; LOURENCETTI, 2014).

Em se tratando do estado brasileiro com maior arrecadação de impostos e com maior PIB, o não atendimento ao previsto na lei federal que criou o piso salarial não pode passar despercebido. Se o piso salarial é instrumento fundamental para garantia de um padrão mínimo de remuneração a ser praticado, se a remuneração é elemento importante para a valorização dos professores e se a desvalorização salarial impacta a qualidade da educação, o descumprimento da lei configura, ao nosso ver, falha grave, que tende a ter desdobramentos negativos na educação de parcela significativa das crianças e jovens brasileiros, uma vez que, como exposto aqui, o estado de São Paulo concentra o maior número de matrículas na rede pública no Brasil.

Recebido em abril de 2016 e aprovado em junho de 2016

\section{Notas}

1 Essa diferença não depende da formação: o PEB I ganha o mesmo salário base independente de ter formação em nível médio ou nível superior.

2 O Bônus Mérito, criado em 2001, prevê o pagamento de bonificação aos professores cujas escolas apresentem bom desempenho no Sistema de Avaliação de Rendimento Escolar do Estado de São Paulo (SARESP). A partir de 2008, o Bônus Mérito passou a ser vinculado ao Índice de Desenvolvimento da Educação do Estado de São Paulo (IDESP) e às metas que a Secretaria da Educação de São Paulo estabelece para cada escola. 


\section{Referências}

APEOESP. Salário Base. Disponível em: <http://www.apeoesp.org.br/salario-base/>. Acesso em 12 abr. 2016.

BARBOSA, Andreza. Os salários dos professores brasileiros: implicações para o trabalho docente. Brasília: Liber Livro, 2011.

BRASIL. Lei n⿳⺈ ${ }^{\mathbf{1 3 0 0 5}}$, de 25 de junho de 2014. Aprova o Plano Nacional de Educação - PNE e dá outras providências. Disponível em: <http://www.planalto.gov.br/ccivil_03/_ato2011-2014/2014/lei/ 113005.htm>. Acesso em: 02 abr. 2016.

. Conselho Nacional de Educação. Câmara de Educação Básica. Resolução CNE/CEB n⿳0 2, de 28 de maio de 2009. Fixa as Diretrizes Nacionais para os Planos de Carreira e Remuneração dos Profissionais do Magistério da Educação Básica Pública. Disponível em: <http://portal.mec.gov.br/ dmdocuments/resolucao_cne_ceb002_2009.pdf>. Acesso em 12 abr. 2016.

. Lei n⿳⺈ 11738, de 16 de julho de 2008. Regulamenta a alínea "e" do inciso III do caput do art. 60 do Ato das Disposições Constitucionais Transitórias, para instituir o piso salarial profissional nacional para os profissionais do magistério público da educação básica. Disponível em: <http://www.planalto. gov.br/ccivil/_Ato2007-2010/2008/Lei/L11738.htm>. Acesso em 02 abr. 2016.

. Lei n⿳⺈ 11494, de 20 de junho de 2007. Regulamenta o Fundo de Manutenção e Desenvolvimento da Educação Básica e de Valorização dos Profissionais da Educação (FUNDEB), de que trata o art. 60 do Ato das Disposições Constitucionais Transitórias; altera a Lei nº 10.195, de 14 de fevereiro de 2001; revoga dispositivos das Leis nº 9.424, de 24 de dezembro de 1996, 10.880, de 9 de junho de 2004, e 10.845, de 5 de março de 2004; e dá outras providências. Disponível em: <http://www.planalto.gov.br/ ccivil_03/_ato2007-2010/2007/Lei/L11494.htm>. Acesso em 02 abr. 2016.

. Lei no 9394, de 20 de dezembro de 1996. Estabelece as diretrizes e bases da educação nacional. Disponível em: <http://www.planalto.gov.br/ ccivil_03/Leis/L9394.htm>. Acesso em 01 abr. 2016.

Constituição (1988). Constituição da República Federativa do Brasil: versão atualizada até a Emenda nº 59, de 2009. Disponível em: <http://www.planalto.gov.br/ccivil_03/constituicao/ constitui\%C3\%A7ao.htm>. Acesso em: 01 abr. 2016.

CASSETTARI; Nathalia; SCALDELAI, Valdelice; FRUTUOSO, Patrícia. Exoneração a pedido de professores: estudo em duas redes municipais paulistas. Educação e Sociedade. Campinas, v. 35, no 128, p. 909-927, jul./set. 2014.

DUARTE, Adriana. Políticas educacionais e o trabalho docente na atualidade: tendências e contradições. In. OLIVEIRA, D. A.; DUARTE, A. M. C. (Org.). Políticas públicas e educação: regulação e conhecimento. Belo Horizonte: Fino Traço, 2011.

FERNANDES, Maria Dilnéia. A valorização dos profissionais da educação básica no contexto das relações federativas brasileiras. Educação e Sociedade, Campinas, v. 34, no 125, p. 1095-1111, out./dez. 2013 . Disponível em <http://www.scielo.br/scielo.php?script=sci_arttext\&pid=S0101$73302013000400005 \& \operatorname{lng}=$ pt\&nrm=iso $>$. Acesso em 22 abr. 2016.

FERNANDES, Maria José. BARBOSA, Andreza. O trabalho docente na rede pública do estado de São Paulo: apontamentos iniciais para a discussão da jornada de trabalho. Práxis Educacional, Vitória da Conquista, v. 10, no 17, p. 117-142, jul./dez. 2014. Disponível em: <http://periodicos.uesb.br/index.php/ praxis/article/viewFile/4531/4332>. Acesso em. 18 abr. 2016. 
G1. Piso salarial dos professores terá reajuste de 11,36\% em 2016, 14 jan. 2016. Disponível em: <http:// g1.globo.com/educacao/noticia/2016/01/piso-salarial-dos-professores-tera-reajuste-de-1136-em-2016diz-mec.html>. Acesso em 12 abr. 2016.

GATTI, Bernardete. Reconhecimento social e as políticas de carreira docente na educação básica. Cadernos de Pesquisa, São Paulo, v. 42, nº 145, p. 88-111, jan./abr. 2012.

et. al. A atratividade da carreira docente no Brasil. Estudos \& Pesquisas Educacionais, São Paulo, nº 1, p. 139-209, mai. 2010.

IBGE. Contas regionais do Brasil 2012. Contas Nacionais, Rio de Janeiro, nํㅡㄹ, 2014.

INEP. Sinopse Estatística da Educação Básica. Brasília: INEP, 2014. Disponível em: <http://portal.inep.gov. br/basica-censo-escolar-sinopse-sinopse>. Acesso em: 13 abr. 2016.

LAPO, Flavinês; BUENO, Belmira. Professores: desencanto com a profissão e abandono do magistério. Cadernos de Pesquisa, São Paulo, nº 118, p. 65-88, mar. 2003.

LOURENCETTI, Gisela. A baixa remuneração dos professores: algumas repercussões no cotidiano da sala de aula. Revista de Educação Pública. Cuiabá, v. 23, no 52, p. 13-32, jan./abr. 2014. Disponível em: <http:// periodicoscientificos.ufmt.br/index.php/educacaopublica/article/view/1422/pdf>. Acesso em 01 abr. 2016.

MEC. Piso Salarial Profissional Nacional - Lei nº 11.738, de 16 julho de 2008. Disponível em: <http:// portal.mec.gov.br/piso-salarial-de-professores>. Acesso em 12 abr. 2016.

MONLEVADE, João. Valorização salarial dos professores: o papel do piso salarial profissional nacional como instrumento de valorização dos professores da educação básica pública. 2000. 315 f. Tese (Doutorado em Educação) - Faculdade de Educação, Universidade Estadual de Campinas, Campinas, 2000.

O ESTADO DE SÃO PAULO. Nalini: São Paulo está abaixo do piso federal do professor, São Paulo, 09 abr.2016. Disponível em: <http://educacao.estadao.com.br/noticias/geral,nalini-sp-esta-abaixo-do-pisofederal-do-professor,10000025658>. Acesso em: 12 abr. 2016.

OLIVEIRA, Dalila. Política Educacional e a Re-Estruturação do Trabalho Docente: reflexões sobre o contexto latino-americano. Educação e Sociedade, Campinas, v. 28, no 99, p. 355-375, mai./ago. 2007.

RECEITA FEDERAL DO BRASIL. Arrecadação UF jan. a dez. 2015. Disponível em: <http://idg.receita. fazenda.gov.br/dados/receitadata/arrecadacao/arrecadacao-por-estado/arrecadacao-uf-2015/ arrecadacao-por-uf-internet-jan-dez15.ods/view>. Acesso em 12 abr. 2016.

ROCHA, Maria da Consolação. Políticas de valorização do magistério: remuneração, plano de carreira, condições de trabalho - uma análise da experiência de Belo Horizonte, 2009. 393f. Tese (Doutorado em Educação) - Universidade de São Paulo, São Paulo, 2009.

SÃO PAULO. Secretaria da Educação. Resolução SE no 8, de 19 de janeiro de 2012. Dispõe sobre a carga horária dos docentes da rede estadual de ensino. Disponível em: $<$ http://www.educacao.sp.gov. br/lise/sislegis/detresol.asp?strAto=201201190008>. Acesso em: 18 abr. 2016.

. Lei Complementar no 1094, de 16 de julho de 2009. Institui a Jornada Integral de Trabalho Docente e a Jornada Reduzida de Trabalho Docente para os integrantes do Quadro do Magistério da Secretaria da Educação, cria cargos de docente que especifica e dá outras providências correlatas. Disponível em: <http://www.jusbrasil.com.br/legislacao/818278/lei-complementar-1094-09-sao-paulosp>. Acesso em 13 abr. 2016.

SEE-SP. Secretaria da Educação do Estado de São Paulo. 2016a. Disponível em: <http://www. educacao.sp.gov.br/portal/institucional/>. Acesso em 13 abr. 2016. 
Coordenadoria de Gestão de Recursos Humanos. Docentes - resumo gerencial. 2016b.

Disponível em: <http://www.educacao.sp.gov.br/cgrh/wp-content/uploads/2016/03/2-HistoricoClasses-Docentes_0216.pdf >. Acesso em 13 abr. 2016.

Secretaria da Educação institui jornada de trabalho de dois terços em sala de aula para

professores. 20 de janeiro de 2012. Disponível em: <http://www.educacao.sp.gov.br/noticias/secretariada-educacao-institui-jornada-de-trabalho-de-dois-tercos-em-sala-de-aula-para-professores-2>. Acesso em 18 abr. 2016.

SOUZA, Aparecida Neri. As políticas educacionais para o desenvolvimento e o trabalho docente. 1999. 203 f. Tese. (Doutorado em Educação) - Faculdade de Educação, Universidade Estadual de Campinas, Campinas, 1999.

TARTUCE, Gisela; NUNES, Marina; ALMEIDA, Patrícia. Alunos do ensino médio e atratividade da carreira docente no Brasil. Cadernos de Pesquisa, São Paulo, v. 40, no 140, p. 445-477, maio/ago. 2010.

UNESCO. Recomendação relativa à condição dos professores. Paris: UNESCO, 1966. 


\section{The minimum wage in Sao Paulo The devaluation of the teaching profession}

ABSTRACT: The article discusses the current situation of wages and working hours of teachers in the Sao Paulo state public school system in order to verify the adequacy of law no. 11738, of 2008, which created the minimum teaching salary. It provides evidence that the state systematically gets around federal law, accommodating itself in questionable ways, by organising the working day of teachers to the minimum wage level, and furthermore, paying remuneration this year, below the legally established levels, which serves to increase the level of devaluation of teachers.

Keywords: Minimum wage. Valuation of the teaching profession. Teachers remuneration. Sao Paulo state public school network. Teaching work.

\section{Le revenu minimum salarial à Sao Paulo Dévalorisation des professeurs}

RÉSUMÉ: L'article traite de la situation actuelle des salaires et des heures de travail des professeurs du réseau public de l'état de Sao Paulo afin de vérifier la conformité à la Loi nº 11.738, de 2008, qui a crée le revenu minimum des enseignants. On y démontre que l'état dribble systématiquement la législation fédérale, en ajustant de manière discutable les heures de travail des professeurs à la loi du revenu minimum et en versant, cette année, une rémunération en-dessous de ce qui a été établi légalement, ce qui intensifie la dévalorisation des professeurs.

Mots-clés: Revenu minimum. Valorisation de l'enseignement. Rémunération des enseignats des enseignants. Réseau public del'état de Sao Paulo. Travail des enseignants.

\section{El mínimo salarial en São Paulo Desvalorización de los profesores}

RESUMEN: El artículo discute la situación actual de los sueldos y las jornadas laborales de los profesores de la red pública del estado de São Paulo, con el objetivo de comprobar la adecuación a la Ley n⿳ํㅡㄹ 11.738, de 2008, que establece el mínimo salarial del magisterio. Se demuestra que el estado elude la legislación federal, adecuando de manera cuestionable la jornada laboral de los profesores a la ley del mínimo salarial y pagando, este año, una remuneración por debajo de lo establecido por ley, lo cual contribuye a ampliar la desvalorización de los profesores.

Palabras clave: Mínimo salarial. Valorización del magisterio. Remuneración docente. Red pública del estado de São Paulo. Trabajo docente. 